05.1

\title{
Микротвердость и трещиностойкость оксида галлия
}

\author{
(C) В.И. Николаев, А.В. Чикиряка ", Л.И. Гузилова, А.И. Печников \\ Физико-технический институт им. А.Ф. Иофффе РАН, Санкт-Петербург, Россия \\ ๑E-mail: chikiryaka@mail.ru
}

Поступило в Редакцию 19 июля 2019 г.

В окончательной редакции 19 июля 2019 г.

Принято к публикации 22 июля 2019 г.

\begin{abstract}
Методом индентирования алмазной пирамидкой Виккерса исследованы микротвердость и трещиностойкость нескольких типов образцов двух основных политипов оксида галлия: метастабильного $\alpha-\mathrm{Ga}_{2} \mathrm{O}_{3}$ со структурой корунда и $\beta-\mathrm{Ga}_{2} \mathrm{O}_{3}$ (высокотемпературная фаза) с моноклинной кристаллической структурой. Насколько известно авторам, это первая попытка сравнить механические свойства двух политипов оксида галлия.
\end{abstract}

Ключевые слова: оксид галлия, микротвердость, трещиностойкость, механические свойства, метод Виккерса.

DOI: 10.21883/PJTF.2019.21.48476.17991

Кристаллы оксида галлия в настоящее время находятся в поле пристального внимания, поскольку являются одним из самых широкозонных полупроводников и соответственно имеют перспективу множественных приложений $[1,2]$. По этой причине достаточно подробно изучены многие свойства этих кристаллов, в то же время механические характеристики пока исследованы недостаточно. Имеется всего несколько работ, в которых были определены значения микро- и нанотвердости $\beta-\mathrm{Ga}_{2} \mathrm{O}_{3}$ [3-7]. В табл. 1 обобщены результаты, ранее полученные на различных кристаллах и слоях [3-12].

Авторы данного исследования располагали большим набором образцов оксида галлия: как объемными монокристаллами, выращенными из расплава, так и тонкими пленками, полученными путем газотранспортного осаждения на подложки сапфира. Толщина последних составляла $2-10 \mu \mathrm{m}$. Слои $\alpha$ - и $\beta-\mathrm{Ga}_{2} \mathrm{O}_{3}$ были получены в реакторе хлоридной эпитаксии, разработанном для этих процессов ООО „Совершенные кристаллы“ $[13,14]$. Объемные кристаллы были двух типов: коммерческая пластина $\beta-\mathrm{Ga}_{2} \mathrm{O}_{3}$ ориентации (201) и монокристалл твердого раствора $\beta$ - $\left(\mathrm{Al}_{x} \mathrm{Ga}_{1-x}\right)_{2} \mathrm{O}_{3}$ с $x \sim 0.1$, выращенный расплавным методом в сапфировом тигле [15].

Из нескольких существующих вариантов инденторов для определения микротвердости алмазная четырехгранная пирамидка Виккерса используется наиболее часто. Стандартная процедура определения микротвердости состоит в приложении постоянной нагрузки на пирамидку и выдержке в течение $15 \mathrm{~s}$, после чего образец разгружается и производится замер диагонали остаточного отпечатка. Формула для расчета этого значения следующая: $H=1.854 P / d^{2}$, где $P-$ нагрузка, $d-$ диагональ отпечатка. Отпечатки пирамидок на поверхности (0001) $\alpha-\mathrm{Ga}_{2} \mathrm{O}_{3}$ при ее нагружении от 0.2 до $2 \mathrm{~N}$ с помощью микротвердомера ПМТ-3М представлены на рис. 1.

Результаты измерения микротвердости образцов оксида галлия при различных нагрузках приведены в табл. 2. Следует отметить, что значение микротвердости образцов $\alpha-\mathrm{Ga}_{2} \mathrm{O}_{3}$ выше, чем $\beta-\mathrm{Ga}_{2} \mathrm{O}_{3}$, что связано, вероятно, с более плотной упаковкой структуры, подобной корунду $(R 3 m)$, в направлении [0001] для $\alpha-\mathrm{Ga}_{2} \mathrm{O}_{3}$, чем для $\beta-\mathrm{Ga}_{2} \mathrm{O}_{3}$ с моноклинной структурой $(C 2 / m)$. Фотографии отпечатков пирамидки на образцах обоих типов представлены на рис. 2.

При исследовании прочностных свойств относительно хрупких материалов часто используют величину критического коэффициента интенсивности напряжений $K_{1 C}$, характеризующего вязкость разрушения, как одного из

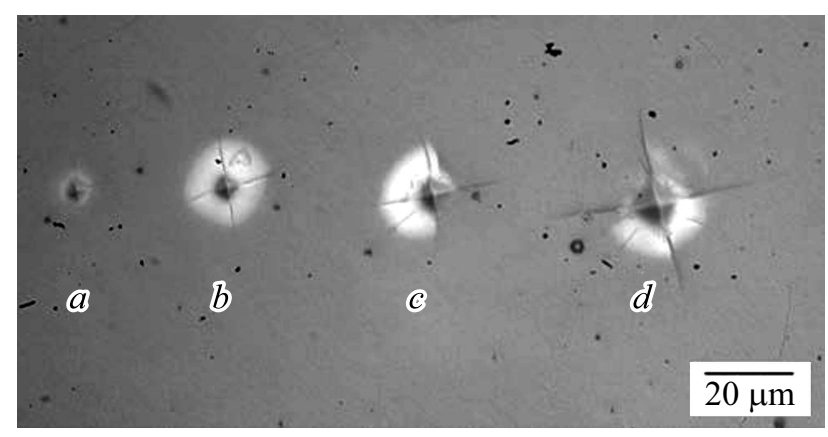

View from the top Side view

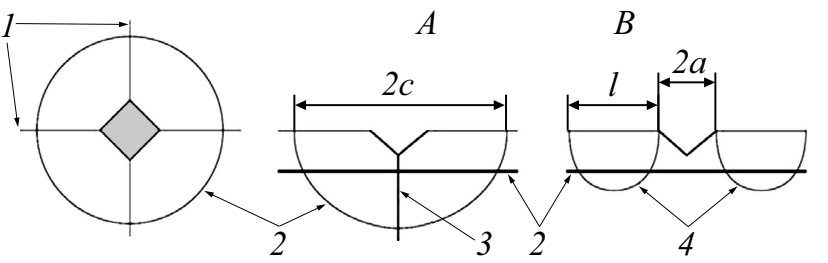

Рис. 1. Последовательность отпечатков пирамидки Виккерса на слое (0001) $\alpha-\mathrm{Ga}_{2} \mathrm{O}_{3}$, нанесенном на сапфир, при четыpex нагрузках: $0.2(a), 0.5(b), 1(c), 2 \mathrm{~N}(d)$. На схеме внизу: 1 - радиальные трещины, 2 - латеральные трещины, 3 - медианные трещины, 4 - трещины Палмквиста. 

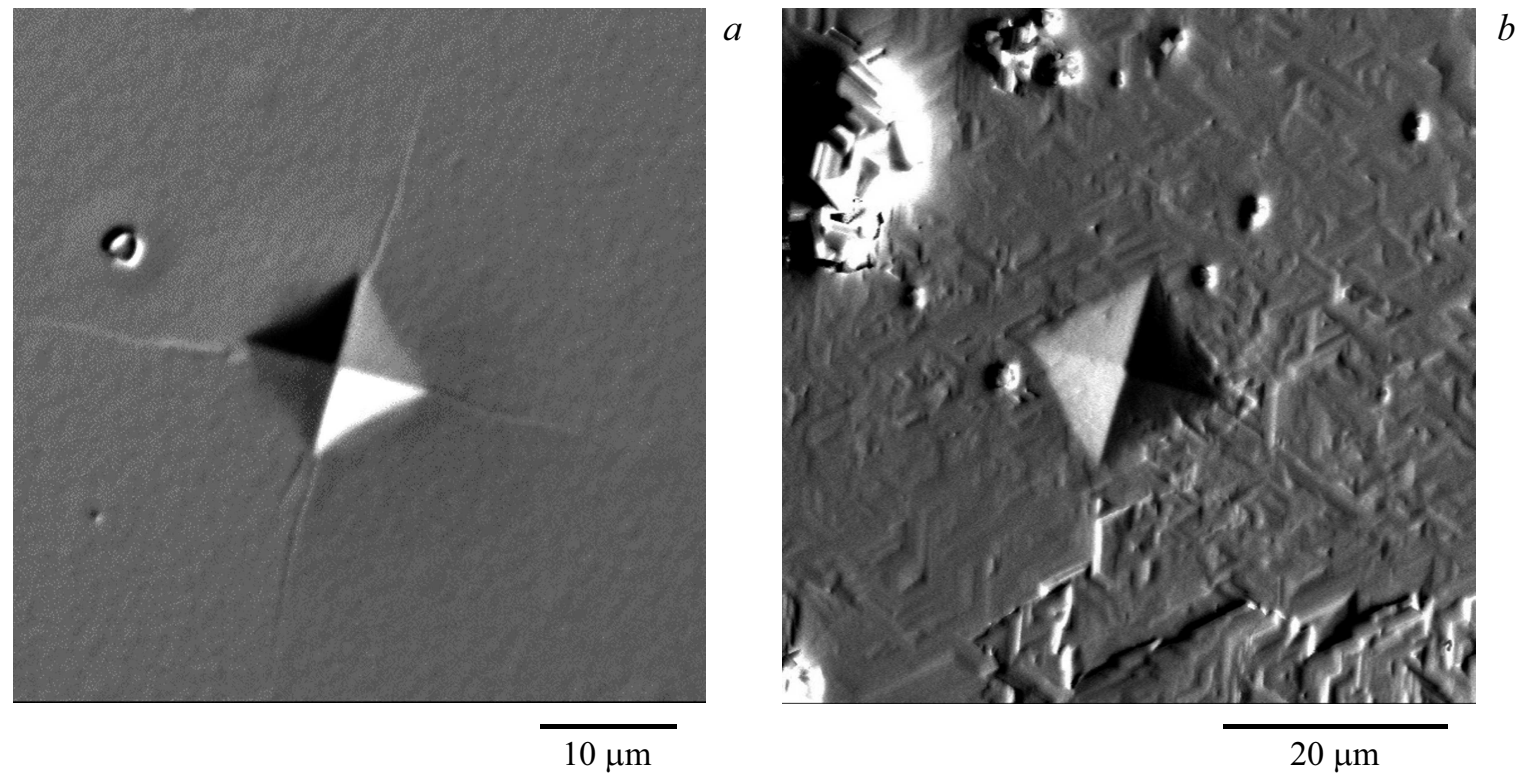

Рис. 2. Вид отпечатка пирамидки (нагрузка $2 \mathrm{~N}$ ) и трещин вблизи него на слоях оксида галлия на сапфире, полученный с помощью сканирующего микроскопа в топографическом режиме. $a-(0001) \alpha-\mathrm{Ga}_{2} \mathrm{O}_{3}, b-(\overline{2} 01) \beta-\mathrm{Ga}_{2} \mathrm{O}_{3}$.

показателей трещиностойкости покрытия. Использование такой характеристики объясняется простотой ее расчета и возможностью определения параметра даже на небольших образцах.
В работе [16] была предложена математическая модель распространения радиальных и медианных трещин вблизи отпечатка, позволяющая определить $K_{1 C}$ (рис. 2,a). Радиальная трещина на поверхности образца

Таблица 1. Сравнение значений микротвердости $H_{V}$, модуля упругости $E$ и трещиностойкости $K_{1 C}$ в кристаллах и слоях оксида галлия (данные [3-7]) и различных полупроводниковых кристаллах в направлении базисной оси (данные [8-12])

\begin{tabular}{|c|c|c|c|c|c|}
\hline $\begin{array}{l}\text { № } \\
\text { п/п }\end{array}$ & Образец & Ориентация & $H_{V}, \mathrm{GPa}$ & $E, \mathrm{GPa}$ & $\begin{array}{l}K_{1 C}\left(K_{1 C P}\right), \\
\mathrm{MPa} \cdot \sqrt{m}\end{array}$ \\
\hline 1 & $\begin{array}{l}\text { Монокристалл, полученный } \\
\text { методом TFM (Tin Flux Method) }\end{array}$ & $(100)$ & $6.5-7.7[3]$ & & \\
\hline 2 & $\begin{array}{l}\text { Монокристалл, выращенный } \\
\text { методом свободной кристаллизации } \\
\text { (Free Crystallization Method) }\end{array}$ & $(100)$ & $8.9[4]$ & $234.0[4]$ & \\
\hline 3 & $\begin{array}{l}\text { Монокристаллы } \beta-\mathrm{Ga}_{2} \mathrm{O}_{3} \text {, } \\
\text { выращенные из расплава методом EFG } \\
\text { (Edge-defined Film-fed Growth Method) }\end{array}$ & $\begin{array}{l}(\overline{2} 01) \\
(101) \\
(100) \\
(010) \\
(001)\end{array}$ & $\begin{array}{c}12.5[5,6] \\
9.7[6] \\
8.5[7] \\
6.55[7] \\
10.3[7]\end{array}$ & $230.0[5,6]$ & \\
\hline 4 & $\begin{array}{l}\left.\text { Слои } \beta-\mathrm{Ga}_{2} \mathrm{O}_{3} / c-\mathrm{Al}_{2} \mathrm{O}_{3} \text { (толщина } \sim 2 \mu \mathrm{m}\right), \text { полученные с помощью } \\
\text { хлорид-гидридной эпитаксии (Hydride Vapour Phase Epitaxy, HVPE) }\end{array}$ & $(\overline{2} 01)$ & $12.5[4]$ & $225.0[4]$ & \\
\hline 5 & $\begin{array}{l}\text { Слои } \alpha-\mathrm{Ga}_{2} \mathrm{O}_{3} / c-\mathrm{Al}_{2} \mathrm{O}_{3}(\text { толщина } \sim 7 \mu \mathrm{m}), \\
\text { полученные с помощью НVРЕ }\end{array}$ & $(0001)$ & 20.4 & $\begin{array}{c}264.0 \\
(\text { расчет) }\end{array}$ & $0.3(0.7)$ \\
\hline 6 & Объемные кристаллы GaN & $(0001)$ & $10.2[8]$ & $295.0[9]$ & $1.1[8]$ \\
\hline 7 & Объемные кристаллы ZnO & $(0001)$ & $5.0[10]$ & $111.2[10]$ & $0.6[8]$ \\
\hline 8 & Объемные кристаллы $\mathrm{Al}_{2} \mathrm{O}_{3}$ & $(0001)$ & $22.0[11]$ & $456.5[12]$ & $6.0[12]$ \\
\hline
\end{tabular}

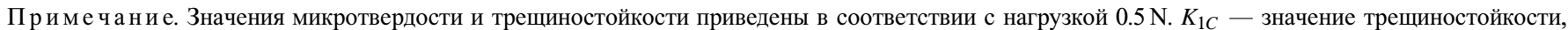
рассчитанное по формуле (1), $K_{1 C P}$ - значение трещиностойкости, рассчитанное по формуле (2). 
Таблица 2. Измеренные значения микротвердости (в GPa) при различных нагрузках на индентор

\begin{tabular}{l|r|r|r|c}
\hline \multirow{2}{*}{ Образец } & \multicolumn{4}{|c}{ Нагрузка, N } \\
\cline { 2 - 5 } & 0.2 & 0.5 & 1.0 & 2.0 \\
\hline $\begin{array}{l}\text { Эпитаксиальный }(0001) \alpha-\mathrm{Ga}_{2} \mathrm{O}_{3} \\
\text { на сапфире (толщина } 7 \mu \mathrm{m})\end{array}$ & 16.7 & 20.4 & 18.9 & 19.4 \\
$\begin{array}{l}\text { Эпитаксиальный }(201) \beta-\mathrm{Ga}_{2} \mathrm{O}_{3} \\
\text { на сапфире (толщина } 9 \mu \mathrm{m})\end{array}$ & - & 12.0 & 10.7 & 11.2 \\
$\begin{array}{l}\text { Объемный кристалл } \\
(100) \beta-\mathrm{Al}_{0.1} \mathrm{Ga}_{0.9} \mathrm{O}_{3}(\text { из расплава }\end{array}$ & 8.3 & 9.1 & 9.2 & - \\
$\begin{array}{l}\text { в сапфировом тигле) } \\
\text { Объемный кристалл }(\overline{2} 01) \beta-\mathrm{Ga}_{2} \mathrm{O}_{3} \\
\text { (коммерческий) }\end{array}$ & 10.8 & 9.0 & 9.7 & - \\
$\begin{array}{l}\text { Объемный кристалл }(010) \beta-\mathrm{Ga}_{2} \mathrm{O}_{3} \\
\text { (коммерческий) }\end{array}$ & 5.7 & 6.2 & 5.9 & -
\end{tabular}

видна и измерима, что и позволяет по значению ее длины сделать оценку вязкости разрушения испытываемого материала.

Существует большое число работ [17-21], в которых рассматривается и обосновывается подход к определению $K_{1 C}$ в опытах по микротвердости. В [17] уточнено значение коэффициента пропорциональности 0.016, после чего выражение для определения $K_{1 C}$ приобрело следующий вид:

$$
K_{1 C}=0.016\left(\frac{E}{H}\right)^{1 / 2} \frac{P}{c^{3 / 2}},
$$

где $P$ - нагрузка, $c$ - длина от центра отпечатка до края трещины, $E$ - модуль Юнга, $H-$ микротвердость по Виккерсу. Данная формула наиболее подходит для так называемой геометрии трещин „half-penny“, характерной для изотропных (керамических) образцов ( $A$ на схеме, показанной внизу на рис. 1).

При разрушении покрытий возникающие в них трещины распространяются через углы остаточного отпечатка в направлении, перпендикулярном границе раздела покрытие-подложка. Для таких трещин (трещины Палмквиста, $B$ на рис. 1) модель расчета величины вязкости разрушения $K_{1 C P}$ была предложена в работе [18]. На наш взгляд, эта модель более подходит для оценки вязкости разрушения в нашем случае. Для расчета $K_{1 C P}$ использовалась формула [20]:

$$
K_{1 C P}=0.015\left(\frac{P}{c^{3 / 2}}\right)\left(\frac{l}{a}\right)^{-1 / 2}\left(\frac{E}{H}\right)^{2 / 3}
$$

где $a$ - половина длины диагонали отпечатка, $c$ длина отрезка от центра отпечатка до края трещины, $l$ - длина трещины Палмквиста.

Зеркально-гладкая поверхность эпитаксиального слоя $\alpha-\mathrm{Ga}_{2} \mathrm{O}_{3}$, обусловленная его высоким структурным ка- чеством [14], позволяет исследовать трещины вблизи отпечатка и оценить $K_{1 C}$ для данного слоя. В случае слоя $\beta-\mathrm{Ga}_{2} \mathrm{O}_{3}$ (рис. $\left.2, b\right)$, полученного в близких условиях, но при более высокой температуре $\left(\sim 1000^{\circ} \mathrm{C}\right)$, явных трещин вблизи отпечатка не обнаружено, что может быть связано с большей пластичностью этого слоя. По данным рентгеновского структурного анализа [13] указанный слой имеет широкие кривые качания и обладает поликристаллической текстурой. Однако трещины не обнаружены нами и при исследовании поверхности (201) монокристаллического образца данной ориентации, что свидетельствует о некоторой закономерности, обусловленной в большей степени особенностью геометрии нагружения, чем качеством материала. Кроме трещин, описываемых упомянутыми выше моделями, нами наблюдались трещины, связанные с кристаллографией кристаллической решетки исследуемых образцов. В случае $\alpha-\mathrm{Ga}_{2} \mathrm{O}_{3}$ на базисной поверхности вблизи отпечатка видны три трещины, расходящиеся под углом, близким к $120^{\circ}$, по плоскостям призмы, а на поверхности (010) монокристаллического образца $\beta-\mathrm{Ga}_{2} \mathrm{O}_{3}-$ две под углом $180^{\circ}$. Такие дополнительные трещины видны и на фотографиях отпечатков на базисной грани сапфира (корунда) [22].

Результаты измерения параметров микротвердости и $K_{1 C}$ для всех исследованных нами объектов представлены в табл. 1 и 2. На рис. 3 показаны результаты вычисления $K_{1 C}$ по экспериментальным данным для двух моделей развития трещин вблизи отпечатка индентора.

Полученные в работе результаты дают представление о твердости и трещиностойкости разных типов образов оксида галлия, что позволяет объективно сравнить данный многофункциональный материал с другими широко используемыми кристаллами. Результат сравнения для близких по структуре политипов важных полупроводниковых кристаллов представлен в табл. 1.

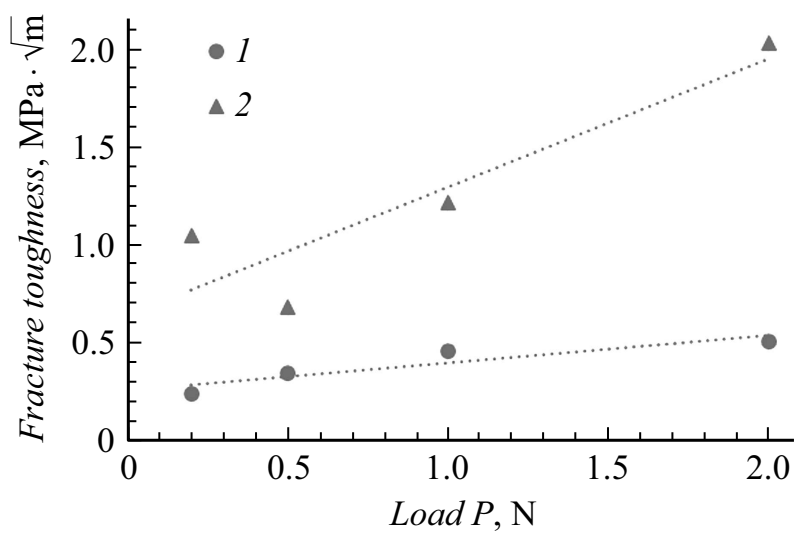

Рис. 3. Зависимость $K_{1 C}$ при индентировании поверхности (0001) слоя HVPE $\alpha-\mathrm{Ga}_{2} \mathrm{O}_{3} / \mathrm{Al}_{2} \mathrm{O}_{3}$ от приложенной нагрузки $P$. $1-K_{1 C}$ (расчет по формуле (1)), $2-K_{1 C P}$ (расчет по формуле (2)). 


\section{Финансирование работы}

Работа поддержана фондом РФФИ и Администрацией Волгоградской области (проект № 18-48-342005).

\section{Конфликт интересов}

Авторы заявляют, что у них нет конфликта интересов.

\section{Список литературы}

[1] Pearton S.J., Yang J., Cary IV P.H., Ren F., Kim J., Tadjer M.J., Mastro M.A. // Appl. Phys. Rev. 2018. V. 5. N 1. P. 011301.

[2] Stepanov S.I., Nikolaev V.I., Bougrov V.E., Romanov A.E. // Rev. Adv. Mater. Sci. 2016. V. 44. N 1. P. 63-86.

[3] Okada S., Kudou K., Higashi I. // Nippon Kagaku Kaishi. 1991. N 10. P. 1426-1430. [In Japanese].

[4] Гузилова Л.И., Гращенко А.С., Печников А.И., Маслов В.Н., Завьялов Д.В., Абдрахманов В.Л., Романов А.Е., Николаев В.И. // Физика и механика материалов. 2016. T. 29. № 2. C. 166-171.

[5] Villora E.G., Arjoca S., Shimamura K., Inomata D., Aoki K. // Proc. of SPIE. 2017. V. 8987. P. 89871 U.

[6] https://www.tamuracorp.com/products/gao/index.html

[7] Mu W., Jia Z., Yin Y., Hu Q., Li Y., Wu B., Zhang J., Tao X. // J. Alloys Compd. 2017. V. 714. P. 453-458.

[8] Yonenaga I. // Mater. Trans. 2005. V. 46. N 9. P. 1979-1985.

[9] Nowak R., Pessa M., Suganuma M., Leszczynski M., Grzegory I., Porowski S., Yoshida F. // Appl. Phys. Lett. 1999. V. 75. N 14. P. 2070-2072.

[10] Kucheyev O., Bradby J.E., Williams J.S., Jagadish C., Swain M.V. // Appl. Phys. Lett. 2002. V. 80. N 6. P. 956-958.

[11] Артемов А.С. // ФТТ. 2004. Т. 46. В. 4. С. 670-678.

[12] Vodenitcharova T., Zhang L.C., Zarudi I., Yin Y., Domyo H., Ho T., Sato M. // J. Mater. Proc. Technol. 2007. V. 194. N 1-3. P. 52-62.

[13] Николаев В.И., Печников А.И., Степанов С.И., Шаробидинов Ш.Ш., Головатенко А.А., Никитина И.П., Смирнов А.Н., Бугров В.Е., Романов А.Е., Брунков П.Н., Кириленко Д.А. // ФТП. 2016. Т. 50. В. 7. С. 997-1000.

[14] Печников А.И., Степанов С.И., Чикиряка А.В., Щеглов М.П., Одноблюдов М.А., Николаев В.И. // ФТП. 2019. T. 53. B. 6. C. $789-792$.

[15] Маслов В.Н., Крымов В.М., Блашенков М.Н., Головатенко А.А., Николаев В.И. // Письма в ЖТФ. 2014. Т. 40. В. 7. C. $56-61$.

[16] Lawn B.R., Evans A.G., Marshall D.B. // J. Am. Ceram. Soc. 1980. V. 63. N 9-10. P. 574-581.

[17] Anstis G.R., Chantiklul P., Lawn B.R., Marshall D.B. // J. Am. Ceram. Soc. 1981. V. 64. N 9. P. 533-538.

[18] Laugier M.T. // J. Mater. Sci. Lett. 1987. V. 6. N 8. P. 897-900.

[19] Cuadrado N., Casellasa D., Angladac M., JiménezPiquéc E. // Scripta Mater. 2012. V. 66. N 9. P. 670-673.

[20] Medeiros E.E., Dias A.M.S. // IJRRAS. 2013 V. 17. N 1. P. 9-18.

[21] Fabijanić T.A., Corić D., Musa M. ̌́, Sakoman M. // Metals. 2017. V. 7. N 4. P. 143.

[22] Носов Ю.Г., Деркаченко Л.И. // ЖТФ. 2003. Т. 73. В. 10. C. $139-142$. 